\title{
Recurrence Risk and Prognostic Parameters in Stage I Rectal Cancers
}

\author{
Sener Cihan ${ }^{1}$, Mehmet Kucukoner ${ }^{2}$ Nuriye Ozdemir ${ }^{3}$, Faysal Dane ${ }^{4}$, Mehmet Ali \\ Nahit Sendur $^{3 *}$, Dogan Yazllıtas ${ }^{3}, Z_{\text {Zuhat Urakci }}{ }^{2}$,Ayse Durnali ${ }^{5}$, Sinemis Yuksel $^{6}$, \\ Sercan Aksoy ${ }^{7}$, Dilsen Colak $^{8}$, Mehmet Metin Seker ${ }^{9}$, Burcu Yapar Taskoylu ${ }^{10}$, \\ Arzu Oguz ${ }^{11}$, Abdurrahman Isikdogan ${ }^{2}$, Nurullah Zengin ${ }^{12}$
}

\begin{abstract}
Background: The standard therapy for stage I rectum cancer is surgical resection. Currently, there is no strong evidence to suggest that any type of adjuvant therapy is beneficial. The risks of local relapse and distant metastasis are higher in rectal tumors. Therefore, while there is no clearly defined absolute indication for adjuvant therapy in lymph node negative colon cancers, rectum tumors that are T3NO and higher require adjuvant treatment. Due to the more aggressive nature of rectal cancers, we explored the clinical and pathologic factors that could predict the risk of relapse in Stage I (T1-T2) disease and whether there was any progression-free survival benefit to adjuvant therapy. Materials and Methods: This multicenter study was carried out by the Anatolian Society of Medical Oncology.A total of 178 patients with rectal cancers who underwent curative surgery between January 1994 and August 2012 in 13 centers were included in the study. Patient demographics, including survival data and tumor characteristics were obtained from medical charts. Results: The median age was 58 years (range 26-85 years). Most tumors were well or moderately differentiated. For adjuvant treatment, 13 patients $(7.3 \%)$ received radiotherapy alone, 12 patients $(6.7 \%)$ received chemotherapy alone and 15 patients $(8.4 \%)$ were given chemoradiotherapy. Median follow up was 29 months (3-225 months). Some 42 patients (23.6\%) had relapse during follow up; 30 with local recurrence $(\mathbf{7 1 . 4 \%})$ whereas 12 (28.6\%) were distant metastases. Among the patients, 5-year DFS was $64 \%$ and OS was $82 \%$. Mucinous histology and receiving adjuvant therapy were found to have statistically insignificant correlations with relapse and survival. Conclusions: In our retrospective analysis, approximately one quarter of patients exhibited either local or systemic relapse. The rates of relapse were slightly higher in the patients who had no adjuvant therapy. There may thus be a role for adjuvant therapy in high-risk stage I rectal tumors.
\end{abstract}

Keywords: Rectal cancer - adjuvant therapy - colon cancer - radiotherapy - prognosis - prognostic factors

Asian Pac J Cancer Prev, 15 (13), 5337-5341

\section{Introduction}

Approximately $30 \%$ of all colorectal cancers consist of rectal cancers (Jemal et al., 2008). Rectal cancer is defined the tumor in the first $12-15 \mathrm{~cm}$ part starting from anal canal (Nelson et al., 2001). Rectal bleeding is the most marked symptom but should not be adequate for proposing further sophisticated investigations (Tong et al., 2014). Screening with fecal occult blood testing by other specialties such as urology and gynecology may increase the awareness and diagnosis for rectal cancer
(Bas et al., 2012). Primary therapeutic modality for the treatment of early stage rectal cancer is surgical resection. Various surgical procedures are administered, according to diffuseness of the primary tumor and the involvement site in the rectum. Surgical techniques range from transanal excision to abdominoperineal resection (APR).

Neoadjuvant/adjuvant chemotherapy and chemoradiotherapy is the standart treatment approach of stage II and III rectal tumors (NIH, 1990). In stage I rectal cancer, standard approach is observation after the surgery because there was no benefit of chemotherapy

Department of Medical Oncology, ${ }^{1}$ Okmeydani Education and Research Hospital, Istanbul, ${ }^{2}$ Dicle University Faculty of Medicine, Diyarbakir, ${ }^{3}$ Yildirim Beyazit University, Ankara, ${ }^{4}$ Marmara University Faculty of Medicine, Istanbul, ${ }^{5}$ Ankara Demetevler Research and Education Hospital, Ankara, ${ }^{6}$ Lutfi Kirdar Kartal Education and Research Hospital, Istanbul, ${ }^{7}$ Hacettepe University Cancer Institute, Ankara, ${ }^{8}$ Diskapi Yildirim Bayazit Education and Research Hospital, Ankara, ${ }^{9}$ Cumhuriyet University Faculty of Medicine, Sivas, ${ }^{10}$ Pamukkale University Faculty of Medicine, Denizli, ${ }^{11}$ Kayseri Education and Research Hospital, Kayseri, ${ }^{12}$ Ankara Numune Education and Research Hospital, Ankara,Turkey*For correspondence: masendur@yahoo.com.tr 
and chemoradiotherapy in resulted trials. However, in this patient group, 5-year local recurrence rate varies between $10 \%$ and $40 \%$, even if it depends on the surgical technique used (Minsky et al., 1988; Chakravarti et al., 1999; Mellgren et al., 2000). The efficacy of adjuvant chemotherapy or radiotherapy after the local excision are very scarce in randomized prospective studies in stage I rectal cancer (Weber et al., 1998). In single-arm studies, especially in T2 stage I rectal cancers, high rate of local recurrence, i.e. $28 \%$, was detected, despite the administration of post-operative chemoradiotherapy (Ota et al., 1992; Bleday et al., 1997; Bouvet et al., 1999; Chakravarti et al., 1999).

Given the high recurrence rates, the patient should be evaluated for the factors that may predict the risk for recurrence, such as tumor depth, lymph node involvement, pathological grade and lymphovascular invasion (Morson et al., 1977; Bleday et al., 1997). Thus, In this multicenter retrospective study, we aimed to investigate the risk factors of local recurrence and survival in operated stage I rectal cancer patients.

\section{Materials and Methods}

Our study was conducted in 13 member centers of Anatolian Medical Oncology Association (ATOD, Anadolu Tıbbi Onkoloji Derneği). The study included 178 patients with Stage I rectal cancer, who presented to the Clinics of Medical Oncology after the curative surgery between January, 1994 and August 2012. The patients who have been operated after neoadjuvant chemoradiotherapy were excluded. Rectal tumor was defined as a tumor localized in the first part of $15 \mathrm{~cm}$ starting from anal canal. The patients were retrospectively examined based on the medical files of each individual center. The patients were re-staged according to 7th version of American Joint Committee on Cancer (AJCC TNM) classification based on pathology reports. Follow-up visit of the patients who remained out of follow-up was performed via telephone by contacting with them or their relatives. During the analysis, the presence of acute abdomen, inadequate lymph node dissection $(<12)$, surgical margin positivity, the presence of lymphovascular invasion, perineural invasion, mucinous pathology or the presence of poorly differentiated tumor was considered as a risk factor.

Disease-free survival (DFS) was defined as the time from diagnosis to local recurrence, distant metastasis, death or last visit after the surgery and overall survival (OS) was defined as the time from diagnosis to death or the last visit after the surgery. Both values were expressed in months.

Statistical analyses were performed using Statistical Package for the Social Sciences (SPSS 13.0) software. Survival analyses were done using Kaplan-Meier method.

\section{Results}

\section{Patients}

Patient characteristics are summarized in Table 1. Median age of the patients was 58 years (min:26, max:85) and male:female ratio was nearly equal to $1(49.4 \%$ and
$50.6 \%)$. Most marked symptom was rectal bleeding $(69.4 \%)$. Almost all patients $(91.6 \%)$ had undergone low anterior resection (LAR) or abdominoperineal resection (APR). In approximately $75 \%$ of the patients, the tumor was localized in the first $10 \mathrm{~cm}$ part.

Given that the number of lymph nodes that should be excised during the rectal cancer surgery is 12 , the number of the patients in whom 11 or less lymph nodes were excised was 90 (50.6\%), whereas the number of the patients in whom 12 or more lymph nodes were excised was $73(41 \%)$. In 15 patients $(8.4 \%)$ who underwent local excision, lymph node was not excised.

According to the poor prognostic criterias, surgical margin positivity was observed in $15(8.8 \%)$ patients. When histological differentiation was examined, 7 $(4.1 \%)$ patients had mucinous adenocarcinoma, $3(1.8 \%)$ patients had poor differentiation, $18(12.6 \%)$ patients had lymphatic invasion and $8(5.8 \%)$ patients had vascular invasion. At least one poor prognostic risk factor was found in $108(63.2 \%)$ patients.

Table 1. Baseline Patients' Demographic and Clinical Properties

\begin{tabular}{|c|c|c|}
\hline \multicolumn{2}{|l|}{ Characteristic } & \multirow{2}{*}{$\frac{\mathrm{n}(100 \%)}{49(27.4 \% \mathrm{v})}$} \\
\hline Median age & $\leq 50$ years & \\
\hline & $>50$ years & $129(72.6 \%)$ \\
\hline \multirow[t]{2}{*}{ Gender } & Male & $88(49.4 \%)$ \\
\hline & Female & $90(50.6 \%)$ \\
\hline \multirow[t]{4}{*}{ Sign } & Rectal bleeding & $104(69.4 \%)$ \\
\hline & Pain & $27(18 . \%)$ \\
\hline & Constipation & $16(10.7 \%)$ \\
\hline & Other & $3(2 \%)$ \\
\hline \multirow[t]{3}{*}{ Distance of the tumor } & $1-5 \mathrm{~cm}$ & $66(37.1 \%)$ \\
\hline & $5-10 \mathrm{~cm}$ & $70(39.3 \%)$ \\
\hline & $10-15 \mathrm{~cm}$ & $42(23.6 \%)$ \\
\hline \multirow[t]{3}{*}{ ECOG } & $0-1$ & $130(84.4 \%)$ \\
\hline & $2-3$ & $22(14.3 \%)$ \\
\hline & 4 & $2(1.3 \%)$ \\
\hline \multirow[t]{3}{*}{ Surgery } & Low anterior resection & $95(53.4 \%)$ \\
\hline & Abdominoperineal resection & $68(38.2 \%)$ \\
\hline & Local excision & $15(8.4 \%)$ \\
\hline \multirow[t]{3}{*}{ Histologic differentiation } & Good & $75(46.8 \%)$ \\
\hline & Intermediate & $82(51.4 \%)$ \\
\hline & Poor & $3(1.8 \%)$ \\
\hline \multirow[t]{2}{*}{ Tumor stage } & $\mathrm{T} 1$ & $30(16.8 \%)$ \\
\hline & $\mathrm{T} 2$ & $148(83.2 \%)$ \\
\hline \multirow[t]{2}{*}{ Recurrence status } & Local recurrence & $30(16.9 \%)$ \\
\hline & Distant metastasis & $12(6.7 \%)$ \\
\hline \multirow[t]{3}{*}{ Number of lymph nodes } & $1-11$ & $90(50.6 \%)$ \\
\hline & $\geq 12$ & $73(41 \%)$ \\
\hline & Unexcised & $15(8.4 \%)$ \\
\hline
\end{tabular}

Table 2. Recurrence Rates in T1-T2 Rectal Cancer according to the Adjuvant Therapy

\begin{tabular}{lccccc}
\hline Stage & \multicolumn{2}{c}{ Adjuvant Therapy $(\%)$} & \multicolumn{3}{c}{ Recurrence } \\
\cline { 4 - 6 } & & $6(3.4)$ & 0 & 0 & 0 \\
\hline T1 & Yes & $24(13.4)$ & 5 & 2 & 7 \\
& No & $34(19.1)$ & 3 & 0 & 3 \\
T2 & Yes & $114(64.1)$ & 22 & 10 & 32 \\
& No & $178(100)$ & 30 & 12 & 42 \\
\hline
\end{tabular}




\section{Treatment}

Among all patients, a total of $40(22.4 \%)$ patients were treated with adjuvant therapy $(7.3 \%$, only with radiotherapy; $6.7 \%$, only with chemotherapy; and $8.4 \%$, with chemoradiotherapy). Of the patients who were treated with adjuvant therapy, $6(3.4 \%)$ had $\mathrm{T} 1$ tumor, whereas others had T2 tumor (Table 2). Of 15 patients with surgical margin positivity, 4 were reoperated, whereas 5 received adjuvant therapy. The remaining 6 patients did not accept any additional therapy.

It was seen that the decision to receive adjuvant therapy was made by the patients with known risk factors, such as surgical margin positivity, histological grade, the presence of mucinous component, lymphovascular invasion and insufficient lymph node dissection. According to the presence of any risk factor, $78.0 \%$ of the patients who treated with adjuvant therapy had at least one poor prognostic risk factor, whereas $57.5 \%$ of the patients not treated with adjuvant therapy had at least one poor prognostic risk factor and this difference was statistically significant $(\mathrm{p}=0.01)$.

\section{Recurrence and survival}

Median follow-up of this study was 29 (3-225) months. Within this period of time, recurrence was occurred in 42 $(23.6 \%)$ patients and 30 of recurrences $(71.4 \%)$ were local

Table 3. Parameters that May Effect Disease-free Survival

\begin{tabular}{|c|c|c|c|}
\hline Characteristic & $\mathrm{N}(\%)$ & 5-year DFS & $\mathrm{P}$ value \\
\hline Gender & & & 0.98 \\
\hline Male & $88(49.4 \%)$ & $60 \%$ & \\
\hline Female & $90(50.6 \%)$ & $70 \%$ & \\
\hline Distance of the tumor & & & 0.69 \\
\hline $1-5 \mathrm{~cm}$ & $66(37.1 \%)$ & $62 \%$ & \\
\hline $5-10 \mathrm{~cm}$ & $70(39.3 \%)$ & $60 \%$ & \\
\hline $10-15 \mathrm{~cm}$ & $42(23.6 \%)$ & $69 \%$ & \\
\hline Histologic differentiatio & & & 0.57 \\
\hline Good & $75(46.8 \%)$ & $46 \%$ & \\
\hline Intermediate & $82(51.2 \%)$ & $51 \%$ & \\
\hline Poor & $3(2 \%)$ & $75 \%$ & \\
\hline Mucinous histology & & & 0.19 \\
\hline Yes & $7(4.1 \%)$ & $66 \%$ & \\
\hline No & $164(95.9 \%)$ & $64 \%$ & \\
\hline Lenfovasculer invasion & & & 0.967 \\
\hline Yes & $18(12.6 \%)$ & $66 \%$ & \\
\hline No & $125(87.4 \%)$ & $83 \%$ & \\
\hline Tumor stage & & & 0.57 \\
\hline $\mathrm{T} 1$ & $30(16.8 \%)$ & $66 \%$ & \\
\hline $\mathrm{T} 2$ & $148(83.2 \%)$ & $63 \%$ & \\
\hline Number of lymph nodes & & & 0.59 \\
\hline Sufficient $(\geq 12)$ & $73(41.0 \%)$ & $66 \%$ & \\
\hline Insufficient $(<11)$ & $105(59.0 \%)$ & $62 \%$ & \\
\hline Surgical margin & & & 0.23 \\
\hline Positive & $15(8.8 \%)$ & $44 \%$ & \\
\hline Negative & $156(91.2 \%)$ & $66 \%$ & \\
\hline Risk Factor & & & 0.25 \\
\hline Yes & $108(63.2 \%)$ & $61 \%$ & \\
\hline No & $63(36.8 \%)$ & $69 \%$ & \\
\hline Adjuvant therapy & & & 0.15 \\
\hline Yes & $40(22.4 \%)$ & $70 \%$ & \\
\hline No & $138(87.6 \%)$ & $63 \%$ & \\
\hline
\end{tabular}

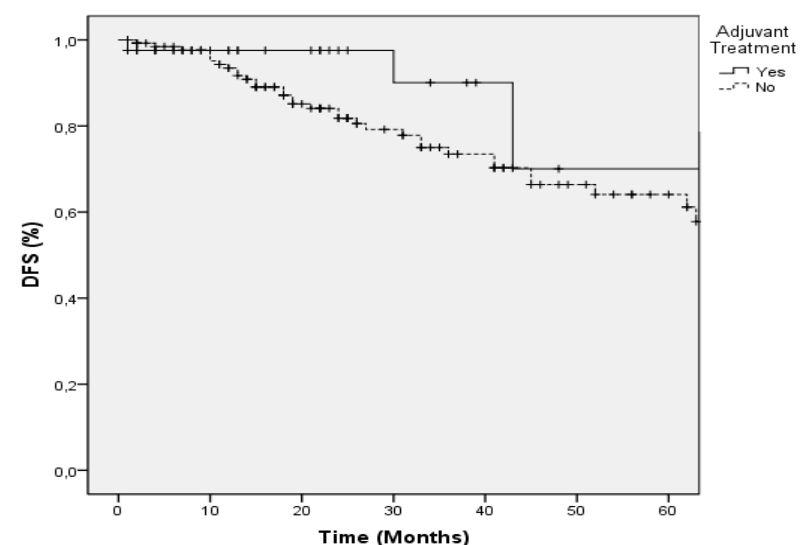

Figure 1. Disease-Free Survival According to Adjuvant Therapy

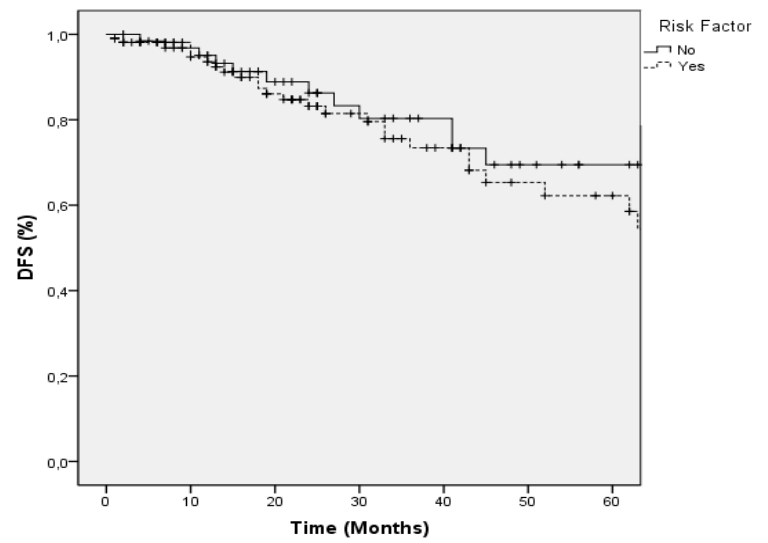

Figure 2. Disease-Free Survival According to the at Least One Risk Ffactor

whereas $12(28.6 \%)$ were distant metastases (Table 2).

When the recurrence was evaluated according to receiving adjuvant chemotherapy by whether nearly all recurrences $(92.8 \%)$ were seen in the patients who did not receive adjuvant therapy the patient received adjuvant therapy (Table 2). In the subgroup analyses, recurrence rate was $7.5 \%$ in the patients who received adjuvant therapy whereas it was $28.3 \%$ in those who did not receive adjuvant therapy and the difference was statistically significant $(\mathrm{p}=0.031)$. The recurrence rate was $25.0 \%$ in the patients with any risk factor and $19.0 \%$ in the patients without risk factor and the difference was not statistically significant $(\mathrm{p}=0.25)$.

According to the survival data, median DFS and OS could not be reached due to the low events. Among the patients, 5 -year DFS was $64 \%$ and OS was $82 \%$. When clinical and pathological parameters that may affect DFS and OS were evaluated, none of the factors showed a significant effect on 5-year DFS and OS. (Table 3) (Figure 1, Figure 2).

\section{Discussion}

In operated patients with Stage I rectal cancer, standard approach is follow-up without adjuvant therapy. In this patient group, 5-year local recurrence rate varies between 10 and $40 \%$, even if it depends on the surgical technique 
used (Minsky et al., 1998; Chakravarti et al., 1999; Mellgren et al., 2000). These differences of recurrence rates may be explained by retrospective design of the majority of the studies and the heterogeneity of the patient groups. There are some publications that suggest that total mesorectal excision is the surgical technique with the lowest rate of local recurrence (Enker et al., 1995; Arbman et al., 1996; Heald et al., 1998; Carlsen et al., 1998; Havenga et al., 1999; Leo et al., 2000).

Prospective studies for adjuvant therapy in the group with Stage I rectal cancer are limited (Steele et al.,1999; Russell et al., 2000). Although it is known that poor risk factors such as surgical margin positivity, the presence of mucinous component, histological grade and the presence of lymphovascular invasion can influence the decision about adjuvant therapy in the case of stage II rectal cancer, there are no clear data that showed the prognosticity in stage I tumors (Ota et al., 1992; Bailey et al., 1992; Minsky et al., 1994; Fortunato et al., 1995; Bleday et al., 1997; Taylor, et al. 1998). In a recently study showed high pre-treatment neutrophil/lymphocyte ratio is a significant independent predictor of shorter survival in patients with colorectal cancer (Ozdemir et al., 2014). In our study, we aimed to determine the parameters that may affect the recurrence and the life expectancy in stage I rectal cancer.

Of the patients enrolled to our study, $63.2 \%$ had at least one of previously defined risk factors. During the follow-up, a total of 42 (23\%) patients developed local recurrence or distant metastasis. When the data for the risk factors that may affect the recurrence was examined, none of the risk factors reached the significance statistical value. However, it should be considered that a substantial part of the patients with risk factors received adjuvant therapy and the number of patients was small.

In the tumors localized in the lower one third of the rectum, lymph node positivity was found to be $34 \%$ (Nascimbeni et al., 2002). In Stage I tumors, this rate is 10-20\% (Blumberg et al., 1999). Given that, in colorectal cancer, the minimum number of lymph node that should be excised is 12 , approximately $40 \%$ of our patients had undergone sufficient lymph node dissection. Based on our results, the fact that 30 of 42 patients with recurrence had local recurrence reinforces the likelihood of microscopic residual tumor that remained.

Surgical margin positivity is an important risk factor for the recurrence of rectal cancer (Compton et al., 2000; Nagtegaal et al., 2008). In a recently study showed that intra-operative rectal washout with mere saline solution largely reduces the risk of anastomotic recurrences in patients with resectable rectal cancer (Can Zhou et al., 2013). However, in the study performed by Philip et al., (2002) a significant correlation between surgical margin positivity and local recurrence could not be demonstrated in the case of stage I rectal cancer. They explained these findings by the inclusion of the patients in the risk group due to surgical margin positivity and the intake of adjuvant therapy.

In our study, 6 of 10 patients $(54.5 \%)$ with surgical margin positivity, who did not receive adjuvant therapy, developed local recurrence, whereas only 1 of 5 patients (20\%) who received adjuvant chemoradiotherapy developed local recurrence. Although these rates do not reach a statistical significance due to small number of patients, these findings suggest that adjuvant chemoradiotherapy is effective in the presence of surgical margin positivity.

Although all of 6 patients with T1 tumor burden, who received adjuvant therapy, had at least one risk factor, none of them developed a recurrence. Nevertheless, only 1 of 7 patients with $\mathrm{T} 1$ tumor, who showed recurrence without adjuvant therapy (5 local recurrences, 2 distant metastases) had surgical margin positivity as a risk factor. While only 3 of 34 patients $(8.8 \%)$ with T2 tumor burden, who received adjuvant therapy, developed local recurrence, 32 of 114 patients $(28 \%)$ who did not receive adjuvant therapy developed recurrence (22 local recurrences, 10 distant metastases). In the light of these data, previous administration of adjuvant therapy significantly decreases the risk for recurrence $(p=0.031)$. In the study performed by Madhulika G. et al., none of 13 patients with Stage I rectal cancer who received adjuvant therapy showed local recurrence or distant metastasis, whereas 7 of 37 patients who did not receive adjuvant therapy showed local recurrence and this difference was statistically significant $(\mathrm{p}=.02)$ (Madhulika et al., 1999).

In the study performed by Philip et al. (2002), of 125 patients with stage I rectal cancer, 15 were treated with adjuvant chemoradiotherapy and 16 were treated with radiotherapy alone. At the end of a median follow-up of 6.7 years, no difference was observed in local recurrence, distant metastasis and overall survival rates, whereas median time to local recurrence was 2.1 years in the group treated with adjuvant therapy and 1.1 years in the group that did not take adjuvant therapy (Philip et al., 2002).

In our study with median follow-up time of 29 (3225) months, 5-year DFS was $64 \%$ and OS was $82 \%$, consistently with the literature (Jessup et al., 1992; Zaheer et al., 1998; Heald et al., 1998; Madhulika et al., 1999; By et al. 2002). When the data for the factors that may affect DFS were evaluated, the significant contribution of any clinical or pathological factor to the results was not demonstrated.

Consequently, in the patients with stage I rectal cancer, standard approach is still observation without adjuvant treatment. However, given the high rates of recurrence, the predictors of the recurrence should be defined. Although our study only showed that previous intake of adjuvant therapy decreased the risk for recurrence, this did not lead to DFS and OS. There may be a role for adjuvant therapy in high-risk stage I rectal tumors. However, there is still a need for prospective studies in this regard.

\section{References}

Arbman G, Nilsson E, Hallbik O, et al (1996). Local reccurence following total mesorectal excision for rectal cancer. $\mathrm{Br} J$ Surg, 83, 375-9.

Bailey HR, Huval WV, Max E, et al (1992). Local excision of carcinoma of the rectum for cure. Surgery, 111, 555-1.

Bas K, Guler T, Gunay LM, et al (2012). Public awareness of colorectal cancer in a turkish population: importance of fecal occult blood testing. Asian Pac J Cancer Prev, 13, 195-8

Bleday R, Breen E, Jessup JM, et al (1997). Prospective 
evaluation of local excision for small rectal cancers. Dis Colon Rectum, 40, 388-2.

Bleday R. (1997). Local excision of rectal cancer. World J Surg, 21, 706-4.

Blumberg D, Paty PB, Guillem JG, et al (1999). All patients with small intramural rectal cancers are at risk for lymph node metastasis. Dis Colon Rectum, 42, 881-5.

Bouvet M, Milas M, Giacco GG, et al (1999). Predictors of recurrence after local excision and postoperative chemoradiation therapy of adenocarcinoma of the rectum. Ann Surg Oncol, 6, 26-2.

By JE, Tepper M, O'Connell, et al (2002). Adjuvant therapy in rectal cancer: analysis of stage, sex and local control-final report of intergroup. J Clin Oncol, 20, 1744-0.

Can Zhou, Yu Ren, Ke Wang, et al (2013). Intra-operative rectal washout with saline solution can effectively prevent anastomotic recurrence: a meta analysis. Asian Pac J Cancer Prev, 14, 7155-9.

Carlsen E, Schlichting E, Guldvog I, et al (1998). Effect of the introduction of total mesorectal excision for the treatment of rectal cancer. Br J Surg, 85, 526-9.

Chakravarti A, Compton CC, Shellito PC, et al (1999). Longterm follow-up of patients with rectal cancer managed by local excision with and without adjuvant irradiation. Ann Surg, 230, 49-4.

Compton CC, Fielding LP, Burgart LJ, et al (2000). Prognostic factors in colorectal cancer. College of American Pathologists Consensus Statement, 1999. Arch Pathol Lab Med, 124, 979-94.

Enker WE, Thaler HT, Cranor ML, et al (1995). Total mesorectal excision in the operative treatment of carcinoma of the rectum. J Am Coll Surg, 181, 335-46.

Fortunato L, Ahmad NR, Yeung RS, et al (1995). Long-term follow-up of local excision and radiation therapy for invasive rectal cancer. Dis Colon Rectum, 38, 1193-9.

Havenga K, Enker WE, Norstein J, et al (1999). Improved survival and local control after total mesorectal excision or D3 lymphadenectomy in the treatment of primary rectal cancer: An international analysis of 1411 patients. Eur J Surg Cancer, 25,368-4

Heald RJ, Moran BJ, Ryall RD, et al (1998). Rectal cancer: The Basingstoke experience of total mesorecal excision, 19781997. Arch Surg, 133, 894-9.

Jemal A, Siegel R, Ward E (2008). Cancer statistics 2008. CA Cancer J Clin, 58, 71-96,

Jessup JM, Stewart AK, Menck HR (1998). The national cancer data base report on patterns of care for adenocarcinoma of the rectum, 1985-1995. Cancer, 83, 2408-8.

Leo E, Belli F, Andreola S, et al (2000). Total rectal resection and complete mesorectal excision followed by coloendoanal anastomosis as the optimal treatment for low rectal cancer: The experience of the National Cancer Institute of Milano. Ann Surg Oncol, 7, 125-2.

Madhulika G, Varma MD, Stanley J, et al (1999). Local excision of rectal carcinoma. Arch Surg, 134, 863-8.

Mellgren A, Sirivongs P, Rothenberger DA, et al (2000). Is local excision adequate therapy for early rectal cancer? Dis Colon Rectum, 43, 1064-1.

Minsky BD, Mies C, Recht A, et al (1988). Resectable adenocarcinoma of the rectosigmoid and rectum. I. Patterns of failure and survival. Cancer, 61, 1408

Minsky BD, Enker WE, Cohen AM, et al (1994). Local excision and postoperative radiation therapy for rectal cancer. Am J Clin Oncol, 17, 411- 6.

Morson BC, Bussey HJ, Samoorian S (1977). Policy of local excision for early cancer of the colorectum. Gut, 18, 1045-0.

Nascimbeni R, Burgart L, Nivatvongs S, et al (2002). Risk of lymph node metastasis in T1 carcinoma of the colon and rectum. Dis Colon Rectum, 45, 200-6.

Nagtegaal ID, Quirke P (2008). What is the role for the circumferential margin in the modern treatment of rectal cancer? J Clin Oncol, 26, 303-12.

Nelson H, Petrelli N, Carlin A (2001). Guidelines 2000 for colon and rectal cancer surgery. J Natl Cancer Inst, 93, 583-96.

NIH Consensus Conference. (1990). Adjuvant therapy for patients with colon and rectal cancer. JAMA, 264, 1444-0.

Ota DM SJ, Rich TA (1992). M. D. Anderson Cancer Center experience with local excision and multimodality therapy for rectal cancer. Surg Oncol Clin North Am, 1, 147-2.

Ozdemir Y, Akin ML, Sucullu I, et al (2014). Pretreatment neutrophil/lymphocyte ratio as a prognostic aid in colorectal cancer. Asian Pac J Cancer Prev, 15, 2647-0.

Paty PB, Nash GM, Baron P, et al (2002) Long-term results of local excision for rectal cancer. Ann Surg. 236, 522-30.

Russell AH, Harris J, Rosenberg P, et al (2000). Anal sphincter conservation for patients with adenocarcinoma of the distal rectum: long-term results of Radiation Therapy Oncology Group protocol 89-02. Int J Radiation Oncology Biol Phys, 46, 313-2.

Steele GD, Herndon JE, Bleday R, et al (1999). Sphincter-sparing treatment for distal rectal adenocarcinoma. Ann Surg Oncol, 6, 433-1.

Taylor RH, Hay JH, Larsson SN. (1998). Transanal local excision of selected low rectal cancers. Am J Surg, 175, 360-3.

Tong G, Chai J, Cheng J, et al (2014). Diagnostic value of rectal bleeding in predicting colorectal cancer: a systematic review. Asian Pac J Cancer Prev, 15, 1015-1

Weber TK, Petrelli NJ. (1998). Local excision for rectal cancer; an uncertain future. Oncology, 12, 933-3.

Zaheer S, Pemberton JH, Farouk R, et al (1998). Surgical treatment of adenocarcinoma of the rectum. Ann Surg. 227, 800-11. 